\title{
Alfabetizações: desafios da nova mídia
}

\author{
口 Pedro Demo*
}

\section{Resumo}

O desafio da alfabetização ganhou nova dimensão com o mundo digital, em particular com novos textos virtuais. A alfabetização tradicional - ler, escrever e contar - torna-se mero pressuposto, já que nenhuma criança deixa de usar o computador por não saber ler e escrever. Em conseqüência, o termo é usado no plural, primeiro, para indicar o contexto sócio-histórico da alfabetização (não apenas técnico), e, segundo, para assinalar novos desafios da iniciação para a vida e para o mercado. De fato, a linguagem usada na escola hoje vai tornando-se apenas uma parte das linguagens de que necessitamos para organizar, construir e reconstruir as oportunidades sociais. A alfabetização deveria ser feita, desde logo, com computador, já na $1^{a}$ série, para proporcionar esta habilidade crucial a todas as crianças. Computador, no entanto, é apenas ferramenta. Não substitui o professor. Para que o computador se torne motivo de aprendizagem, é imprescindível a presença de um professor que saiba unir duas habilidades essenciais: saber alfabetizar e saber lidar com a máquina para construir nela o melhor ambiente possível de alfabetização, em especial usando as simulações virtuais.

Palavras-chave: Alfabetizações. Marginalização digital. Oportunidades digitais.

\section{Abstract \\ Literacies: new media challenges}

Literacy challenge gained new dimension with the digital world, particularly with new virtual texts. Traditional literacy - reading, writing and to count - becomes simple preamble, since no child doesn't use computer because he/she doesn't know how to read or write. Consequently, this term is used plurally, first to indicate the sociohistorical context of literacy (not only technical), and, second to point at new challenges of initiation for life and market. In fact language used at school today is becoming nothing more than a part of the languages needed to organize, construct and reconstruct our social opportunities. Literacy ought to be done, early enough, with the aid of a computer, immediately at the first grade, with the aim to provide this crucial ability for all children. However, computer is a simple tool. It doesn't substitute the teacher. If we want that the computer becomes learning motivation, teacher presence is indispensable, since he has the charge to connect two essential abilities: to know how to do literacy and to know how to cope with the machine, with the objective to construct the best possible literacy environment, specially using virtual simulations.

Keywords: Literacies. Digital divide.

Digital opportunities.

\footnotetext{
* Pós-Doutorado, University of California at Los Angeles; Professor Titular, Universidade de Brasília. E-mail: pedrodemo@uol.com.br
} 
Resumen

\section{Alfabetizaciones: retos de la nueva mídia}

El reto de la alfabetización ganó nueva dimensión con el mundo digital, en particular con nuevos textos virtuales. La alfabetización tradicional - leer, escribir y hacer cuentas - se tornó mero presupuesto, pues ningún niño deja de usar la computadora porque no sabe leer e escribir. En consecuencia, el termino es usado en el plural, primer, para indicar el contexto socio-histórico de la alfabetización (no solo técnico), y, segundo, para señalar nuevos retos de la iniciación para la vida e el mercado. De hecho, el lenguaje utilizado en la escuela de hoy día va tornándose apenas una parte de los lenguajes de que necesitamos para organizar, construir y reconstruir las oportunidades sociales. La alfabetización debería ser hecha, desde luego, con la computadora, ya en la primera serie, para proporcionar esta habilidad crucial a todos os niños. La computadora, entretanto, es solo herramienta. No substituye el maestro. Para que la computadora se torne motivo de aprendizaje es imprescindible la presencia de un maestro que sepa unir dos habilidades esenciales: saber alfabetizar y saber manejar la maquina para construir en ella el mejor ambiente posible de alfabetización, en especial usando las simulaciones virtuales.

Palabras clave: Alfabetizaciones. Marginalización digital. Oportunidades digitales.

Pretende este texto discutir preliminarmente a importância de alargar nossa visão de alfabetização, para irmos muito além do que se faz hoje em sala de aula. Foco principal- mente desafios da nova mídia, entendida esta, ainda que imprecisamente, como tecnologias incorporadas no computador e máquinas similares, tipicamente digitais (DEMO, 2007b, p. 2001). Nem de longe posso dar conta de tamanha discussão, não só porque é ainda recente, mas sobretudo porque engloba polêmicas intermináveis. De modo geral, porém, pode-se dizer que as tecnologias vão bem, obrigado! $\bigcirc$ que vai muito mal é a pedagogia, porque ainda não despertou para esse desafio, fazendo de conta que o mundo real é o mundo da escola. $\mathrm{O}$ que se tem chamado de "sociedade informacional" - para usar a expressão de Castells (1997) - representa para a sociedade como um todo, mas especialmente para os jovens, reptos que exigem capacidade de aprendizagem e inovação muito mais profunda e sistemática, do que decorre a imposição de novos e mais complexos ritos de iniciação. Talvez não se trate de um novo modo de produção, porque o contexto continua capitalista, mas, segundo Castells (1997, p. 17), estamos vivenciando um novo modo de desenvolvimento:

No modo novo e informacional de desenvolvimento a fonte de produtividade está na tecnologia da geração de conhecimento, processamento de informação e comunicação simbólica. Com certeza, conhecimento e informação são elementos críticos em todos os modos de desenvolvimento, já que o processo de produção está sempre baseado em algum nível de conhecimento e no processamento de informação. Contudo, o que é específico para o modo informacional de desenvolvimento é a ação do conhecimento sobre o próprio conhecimento como principal fonte de produtividade. Processamento de informação está focado no aprimoramento da tecnologia do processamento da informação como fonte de produtividade, em círculo virtuoso de inte- 
ração entre fonte de conhecimento de tecnologia e a aplicação de tecnologia para aprimorar a geração de tecnologia e processamento de informação.

Em torno dessas idéias há também euforias excitadas, principalmente neoliberais que prometem mundos e fundos, reduzindo o processo profundo de mudanças a formatos do mercado livre. Se, de um lado, não escapamos de reconhecer que o motor maior da propulsão das mudanças é o mercado capitalista, de outro, é fundamental repor o mercado em sua condição de meio de desenvolvimento, como sempre fizeram críticos iluminados, como Braudel (1993), Polanyi (2000), Dupas (2006). À medida que o mercado se desregula, mantendo o trabalho regulado, torna-se evidente a pretensão do mercado de fazer-se a razão de ser da sociedade, invertendo a relação correta de meios e fins (BAKAN, 2004). Esta crítica, porém, não pode desconhecer que o advento das novas tecnologias acarreta mudanças peremptórias na sociedade e na economia, às quais precisamos responder com devida ética e inteligência. Um bom começo seria a escola, onde ocorre a alfabetização da população. Certamente, alfabetizar-se não é mais apenas ler, escrever e contar, já que isto se torna mero pressuposto. Nenhuma criança deixa de usar computador porque não aprendeu letras e números ela vai lidando com eles naturalmente e os aprende no processo de uso do computador. Não quer isso dizer que não seja útil aprender letras e números de maneira sistemática e adequada, até mesmo para usar todos os dedos ao digitar, mas esta habilidade vai virando pressuposto instrumental, tornando mais claro o que sempre foi: mero ponto de partida. O que importa é o que fazer com letras e números, e agora com tecnologias digitais.

\section{Alfabetizações \\ Idéia da pluralidade da alfabetização}

Para começar, é bom admitir que não há tanta novidade nisso. Se aproximarmos alfabetização aos ritos de iniciação, sempre foram múltiplos, porque a vida exige de cada membro da sociedade uma multiplicidade de competências. Os ritos de iniciação mudaram muito, porque a sociedade também mudou, reclamando de seus membros outras habilidades, à sombra de outros valores e contextos. À medida que a sociedade humana, em especial aquela dominante (eurocêntrica), foi valorizando o estilo letrado de vida em sociedade, "ler, escrever e contar" tornaram-se competências estratégicas. $\bigcirc$ "escriba", não só aquele que sabia escrever, mas em especial aquele que formulava idéias e estratégias para seus senhores, tornava-se figura de proa, desvelando que este tipo de "poder suave" poderia ser efetivo. $\bigcirc$ valor maior da alfabetização tradicional sempre foi a propedêutica do conhecimento, caminho promissor para deter alguma importância em sociedade. Desde sempre, este caminho pavimentava-se menos de ritos mecânicos reprodutivos, do que de habilidades críticas. $\bigcirc$ escriba mais relevante era o crítico, e por isso, nem sempre muito bem-vindo. Bastaria lembrar a noção de conhecimento como pecado, conforme o relato do Gênesis: ao comerem da árvore do conhecimento, Adão e Eva esperavam, de acordo com a sugestão da serpente, que os olhos se abrissem e assim se tornassem deuses. Conhecimento, nesta versão civilizatória, é a centelha divina que persiste no ser humano decaído. Não vale muito ler, escrever e contar de maneira mecânica (MANGUEL, 1996), mas vale muito se isso for o signo da rebeldia contestatória (DEMO, 2004c, 2005a).

Na sociedade letrada, alfabetização passou a ser o rito crucial da preparação para a 
vida e que, advindo o capitalismo, passou a resumir-se à preparação para o mercado. Como sugere loschpe (2004), em sua análise neoliberal escrachada da escola, os pais valorizam educação em sua relação econômica, tornando outras ponderações pedagógicas alusões piegas. Esta iniciação foi de tal modo valorizada, que tornou-se "obrigatória" - entre 6 e 14 anos todos obrigatoriamente devem freqüentar a escola. Em nova fase, esta expectativa é considerada insuficiente, entrando em cena o conceito de alfabetizações, por conta de novos desafios tecnológicos, que, de novo e sempre, não se restringem a dominar comandos, mas idéias (MARTIN; MADIGAN, 2006). Como é usual, tem tudo para ser modismo fátuo, em especial quando se torna determinismo tecnológico, dentro da tese corrente de que a evolução e a história humana são determinados pela tecnologia. Todos os autores críticos combatem essa idéia (BOGOST, 2006; DIJK, 2005; GEE, 2007), mas, na prática, é dominante, em particular porque foi absorvida sofregamente pelo mercado liberal. Não é àtoa que as eras da evolução e história humana são, em geral, demarcadas pela sucessão das descobertas tecnológicas (DEMO, 2002b; LENSKI; LENSKI, 1987).

Embora seja traço mais tipicamente eurocêntrico, em particular no contexto capitalista, o apreço da tecnologia vai além de ser uma face apenas instrumental da trajetória evolucionária e histórica. $\bigcirc$ ser humano - no fundo, a própria natureza - parece ter vinculação umbilical com tecnologia, entendida como estratégia de inovação evolucionária e histórica de sentido autopoiético (MATURANA; VARELA, 1994; MATURANA, 2001). Ao contrário de uma natureza apenas cíclica, reprodutiva, replicativa, entra em cena a percepção de que a natureza é intrinsecamente processo criativo (GOULD, 2002), tipicamente histórico (PRIGOGINE;
STENGERS, 1997; DE LANDA, 1997). Ela é infinita em sua diversidade, o que permite dizer que seus processos e seres são únicos e irreversíveis. Inventar coisas parece ser propriedade humana, ou de uma de suas invenções mais típicas, a engenharia. Mas o maior engenheiro é a natureza, que muda seus seres de maneira avassaladora, assumindo o sentido mais próprio de mudança, ou seja, sem controle (PLANT, 1999). Faz parte dos traços autoritários da sociedade manipular "revoluções gerenciadas" (SOUZA, 2004), aquelas das quais temos o controle para não perdermos o controle. As revoluções naturais são sempre um salto no escuro, como ocorreu quando surgiu a vida e, depois, quando surgiu o ser humano. A natureza produziu um ser que the escapa ao controle, dentro das narrativas milenares da criatura que se volta contra o criador pela via do conhecimento. Agora estamos diante, possivelmente, de um passo similar, quando o ser humano, tendo inventado o computador e a inteligência artificial, poderia, de repente, produzir uma tecnologia que também vai escapar de seu controle (GARDNER, 2007; KURZWEIL, 2005). Máquinas inteligentes poderiam ultrapassar-nos, como já se observa na capacidade muito maior do computador de memória, processamento de dados, cálculos, etc.

Como somos produto da tecnologia natural, é natural que pretendamos nos inovar, por mais que isto seja processo arriscado. Assim, inovar é nosso destino. A questão é a ética da inovação: a quem serve... Esta consideração, por mais que seja incipiente, sugere que o acesso tecnológico é crucial para as oportunidades das pessoas, já que as oportunidades são profundamente condicionadas - não determinadas - pelas tecnologias. Daí advém o tema atual da digital divide, em geral reduzido ao problema do acesso tecnológico (WARSCHAUER, 
2003; DIJK, 2005; WITHROW, 2004). Pelo menos no ambiente eurocêntrico capitalista, - acesso tecnológico costuma ser fatal, já que vencer na vida tende a coincidir com domínio tecnológico. Em vista disso, a alfabetização estaria cada vez mais atrelada a este domínio. Por mais que se sugira, por vezes veementemente (MARTIN; MADIGAN, 2006), que o aspecto crítico e criativo da alfabetização é o que interessa, não o técni$\mathrm{co}, \mathrm{O}$ acesso técnico tende a ser decisivo e seletivo, a começar pela capacidade de consumir tecnologias, sempre restrita a certo poder aquisitivo.

O século XXI, conforme a alusão de Martin (2006), é digitally infused, ou seja, está pervadido pelas tecnologias digitais: vivemos num e-world, "permeado pelos efeitos e produtos da tecnologia eletrônica". "E-negócio, e-comércio, e-cidades, e-saúde, e-governo, e-aprendizagem: ' $e$ ' é pervasivo, ainda que algumas partes do mundo sejam mais afetadas que outras. Neste e-mundo, e-encontros, quer dizer, situações envolvendo contato com ferramentas e facilidades eletrônicas, são lugar comum" (MARTIN, 2006, p. 3). Alfabetização passa a ser vista como acesso a ferramentas múltiplas que capacitam a pessoa a dar conta dos desafios da sociedade e da economia. No entanto, a noção de alfabetização mudou substancialmente no tempo. Na Idade Média, tinha duplo sentido: habilidade de ler e escrever, antes de mais nada, em geral referindo-se a mais que mero domínio de técnicas; e a idéia de pessoa estudada, os literati: participavam da sociedade como alfabetizados, denotando status social elevado e seletivo. Não se pode, porém, esquecer que a alfabetização medieval era predominantemente disciplinar, como observa Manguel (1996), bastando relembrar a visão de Kant (apud VEIGA-NETO, 2001, p. 9):
Enviam-se em primeiro lugar as crianças à escola não com a intenção de que elas lá aprendam algo, mas com o fim de que elas se habituem a permanecer tranqüilamente sentadas e a observar pontualmente o que se lhes ordena, uma vez que a falta de disciplina é um mal pior que a falta de cultura, pois esta pode ser remediada mais tarde, ao passo que não se pode abolir o estado selvagem e corrigir um defeito de disciplina.

A sociedade industrial manteve a noção de elite alfabetizada, mas foi alargada, em parte, para os trabalhadores, em particular da classe média que geria a produtividade. O reconhecimento, porém, da importância da alfabetização para o trabalhador (que induziu sua universalização na Europa) sempre esteve diretamente ligado às funcionalidades do mercado, mais do que à cidadania. Por isso mesmo, muitos críticos acentuaram seu papel "reprodutivo" do sistema (BOURDIEU; PASSERON, 1975), ainda que esta tese seja considerada em parte unilateral (DEMO, 2004c). Pelo final do século XX, a discussão centrou-se na superação do analfabetismo, também por influencia de órgãos internacionais como a UNESCO, sempre insistindo no lado crítico, libertador, de uma alfabetização bem feita, à luz da visão de Paulo Freire (DEMO, 2005c). O sentido político da alfabetização tornava-se proeminente, ainda que a prática escolar raramente correspondesse à expectativa. No início do século XXI, surgem outras referências da alfabetização, citando Martin (2006), nada menos que cinco:

a) alfabetização em TIC (tecnologia da informação e comunicação), dividida em três fases: até metade dos anos 1980, fase da maestria (mastery phase), voltada para domínio de técnicas de manejo; metade dos 1980 até os 1990 tardios, fase da aplicação (application phase), focada em aplicações múlti- 
plas das tecnologias; fim dos 1990 até hoje, fase reflexiva (reflective phase), preocupada com olhares mais críticos; a acentuação voltava-se para superar o mero manejo técnico, em favor da alfabetização questionadora;

alfabetização em TIC é usar tecnologia digital, ferramentas de comunicação e/ou redes de acesso, manejar, integrar e criar informação com o fito de funcionar numa sociedade de conhecimento [...]; os cinco componentes representam um contínuo de habilidades e conhecimento e são apresentados em seqüência sugerindo complexidade cognitiva crescente [...]; i) acessar: conhecer acerca de e como coligir e/ou sacar informação; ii) manejar: aplicar um esquema existente organizacional ou classificatório; iii) integrar: interpretar e representar informação, envolvendo sumariar, comparar e contrastar; iv) avaliar: fazer julgamentos sobre a qualidade, relevância, utilidade ou eficiência da informação; v) criar: gerar informação ao adaptar, aplicar, desenhar, inventar ou fazer-se autor de informação (MARTIN, 2006, p. 10).

\section{Segundo o PISA,}

alfabetização em TIC é o interesse, atitude e habilidade dos indivíduos de apropriadamente usar tecnologia digital e ferramentas de comunicação para acessar, manejar, integrar e avaliar informação, construir novo conhecimento e comunicar-se com outros com o objetivo de participar ativamente na sociedade. (MARTIN, 2006, p. 11);

b) alfabetização tecnológica, vista pelos americanos em geral como condição de competitividade e entendida como "habilidade de usar, manejar e entender tecnologia"; "usar" envolve a operação exitosa dos sistemas chave deste tempo, incluindo conhecer os componentes de macrossistemas existentes ou sistemas adaptativos humanos e como os siste- mas se comportam; "manejar" acarreta assegurar que as atividades tecnológicas sejam manipuladas de modo eficiente e apropriado; "entender" supõe mais do que lidar com fatos e informação, abarcando a habilidade de sintetizar informação em novos insights (MARTIN, 2006, p. 11); sob o signo da competitividade, a alfabetização tecnológica tem sido proposta altissonante de governos norte-americanos, para conectar todas as escolas e salas de aula às supervias de informação, garantir acesso a computadores modernos a todos os professores e estudantes, desenvolver software poderoso e atraente, bem como recursos de aprendizagem on-line dentro do currículo escolar, e assegurar aos docentes capacitação e suporte para poderem auxiliar os estudantes neste tipo de habilidade; autores críticos, entretanto, insistem em que educação tecnológica não se restrinja à relação com o mercado de maneira subserviente, devendo-se promover o debate crítico sobre tecnologia e crescimento econômico;

c) alfabetização em informação, voltada principalmente para student-centred-learning (aprendizagem centrada no estudante), considerada estratégia crucial de aprendizagem com base em locais preferenciais como bibliotecas e comprometida com o cuidado ostensivo por parte dos professores com a aprendizagem do aluno (DEMO, 2004b);

o estudante alfabetizado em informação: i) determina a natureza e extensão da informação necessitada; ii) acessa a informação necessitada efetiva e eficientemente; iii) avalia informação e suas fontes criticamente e incorpora informação selecionada em sua base de conhecimento e sistema de valores; iv) usa informação efetivamente para realizar um propósito específico; v) entende muitas das questões econômicas, legais e sociais que cercam o uso da informação e acessa e usa informação ética e legalmente; 
na Inglaterra, costuma-se arrolar sete pilares desta habilidade: i) identificar qual informação seria o caso usar; ii) propor estratégias para localizar informação relevante; iii) localizar e acessar a informação buscada; iv) comparar e avaliar informação de fontes diferentes; v) organizar, aplicar e comunicar informação; vi) sintetizar e construir em cima da informação em uso; vii) criar nova informação, sobretudo transformar informação em conhecimento; usa-se também a definição da UNESCO:

alfabetização em informação abrange conhecimento das preocupações e necessidades de informação de cada qual e a habilidade de identificar, localizar, avaliar, organizar e efetivamente criar, usar e comunicar informação para dar conta de questões ou problemas à mão; é pré-requisito para participar efetivamente na Sociedade da Informação, e é parte do direito humano básico da aprendizagem ao longo da vida" (MARTIN, 2006, p. 13).

d) alfabetização em mídia, vista como capacidade de avaliar criticamente a mídia de massa e como atividade maior educacional e de pesquisa nos Estados Unidos e Europa; nos Estados Unidos é assumida como uma série de competências de comunicação, incluindo habilidade de acessar, analisar, avaliar e comunicar informação sob muitas formas, impressas e não impressas; interdisciplinar por natureza, aplica-se ao manejo de ambientes eletrônicos complexos e sempre em mudança acelerada, sendo sua propriedade mais fundamental o pensamento crítico;

e) alfabetização visual, alavancada pelo poder da imagem visual, é fundamental para a aprendizagem no mundo atual e nutre-se principalmente da crítica da arte e da arteeducação; a página vai sendo, em grande parte, substituída pela tela como referência dominante de representação e comunicação, afetando profundamente a lógica e a semiótica da leitura; aos poucos torna-se expectativa comum que os textos sejam visualmente bem desenhados.

\section{Preocupação crítica, pelo menos em teoria}

Este modo de ver a alfabetização naturalmente assume sua multiplicidade, passando a ser posta no plural: alfabetizações. Diz-se tratar-se de "novas alfabetizações" quando ultrapassam os textos tipográficos na prática textual, incluindo, entre outros: usar e construir hyperlinks entre documentos e/ou imagens, sons, filmes, linguagens semióticas (tais como emoticons ['risos'] em e-mails, espaço de batepapo on-line, envio de mensagem instantânea), manipular mouse movendo-se dentro de um texto, ler a extensão do arquivo e identificar qual software vai 'ler' cada arquivo, produzir textos 'não lineares', navegar mundos tridimensionais on-line [...] A tendência é definir alfabetizações para além dos conteúdos, entendendo-as como habilidades genéricas, de teor propedêutico. Admite-se que não é o caso pretender que um tipo de alfabetização regule os outros, não só porque mesclam-se na prática, mas também porque o tipo dominante em geral é dos dominantes. A pluralidade pode insinuar visão confusa e dispersa, mas representa a realidade da vida em sociedade marcada, cada vez mais, por perspectivas e situações que variam muito e mantêmse em mudança constante, sem deixar de observar que, por trás, rugem campos de força que empoderam mais a uns que a outros na sociedade. As alfabetizações produzem ou são fruto da ordem social.

A alfabetização digital precisa alimentarse do pensamento crítico, mais que do técnico, condensando, em última instância, "uma habilidade de vida" (MARTIN, 2006, 
p. 19). Claramente postula-se o lugar instrumental da tecnologia que deveria servir aos propósitos éticos humanos. Disto segue a definição de Martin: "Alfabetização digital como consciência, atitude e habilidade dos indivíduos de apropriadamente usar ferramentas digitais e facilidades para identificar, acessar, manejar, integrar, avaliar, analisar e sintetizar recursos digitais, construir novo conhecimento, criar expressões de mídia e comunicar-se com os outros, no contexto de situações específicas de vida, com o objetivo de capacitar ação social construtiva; e refletir sobre tal processo". Martin faz alusão ao termo "digital bildung" (bildung é termo alemão para formação), com a intenção de realçar as pretensões clássicas formativas de processos educacionais.

Reforçando esta expectativa, Mayes e Fowler (2006) ressaltam o foco pedagógico no diálogo em comunidades de aprendizagem, tendo em vista facultar o uso de ferramentas para suporte da participação em grupo e formação de relações de aprendizagem. A tecnologia educacional começou de maneira instrucionista, reprodutivista, favorecendo a mera transmissão de conteúdo', mas finalmente está reconhecendo sua importância para o diálogo crítico e criativo entre os aprendizes, realçando o papel da pesquisa e elaboração. Um dos aspectos mais importantes das novas tecnologias é a oferta de "aprendizagem situada", uma tese muito conhecida de Gee (2004) com relação ao mundo virtual: os designs em 3Ds facultam que se situe a aprendizagem em ambientes que permitem a manipulação ativa do aprendiz. "A aprendizagem como tal não é movida pela tecnologia, mas a tecno- logia está permitindo um princípio fundamental de como as pessoas aprendem a florescer num ambiente novo global" (MAYES; FOWLER, 2006, p. 32). Pode-se, em grande parte, substituir aulas por tarefas de aprendizagem que exigem do aprendiz interação comunitária em ambiente de alfabetização visual, cooperativa e acadêmica.

A educação baseada na internet difere da educação convencional pela ausência de contato físico, e da educação tradicional à distância pelo nível acrescido de interação. Enquanto interação na forma da aula se torna mais difícil on-line, a interação entre aprendizes torna-se mais fácil. As aulas são substituídas por tarefas de aprendizagem que requerem aprendizes interagindo, promovendo um sentimento de comunidade e permitindo a troca de idéias. Também grupos mediados pelo computador podem criar solidariedade através do desenvolvimento de consenso interpretativo. Tarefas de aprendizagem grupal requerem enviar mensagens (MAYES; FOWLER, 2006, p. 38).

Segundo Gilster (2006), há apenas 0.01\% de documentos impressos na nova informação, o que tem imposto mudança radical na biblioteca tradicional. Os estudantes interessam-se cada vez menos por páginas impressas, obtendo sua informação da tela organizada. Ao mesmo tempo, esta interação pode promover a revisão por pares, abrindo campo para um modo de autoria mais participativa. Ao formular um texto, em geral a iniciativa mais corrente é colocá-lo na internet para que todos que quiserem façam seus comentários, o que lembra naturalmente o ambiente de wikipedia ${ }^{2}$. Fala-se, por isso, de uma revolução digital do conhecimento, o que

\footnotetext{
' É notória a obra de Oliveira e Chadwick (1984) sobre tecnologia educacional voltada para "teorias da instrução". Até mesmo Piaget aparece aí como teórico da instrução...

${ }^{2}$ Ambiente de revisão por pares pode ser apreciado no site www.amazon.com onde se oferecem chances ao leitor de avaliar cada obra oferecida; ao lado de avaliações feitas por especialistas, aparecem aquelas feitas por qualquer pessoa interessada.
} 
aponta também para o alfabetismo construído por contextos culturais, políticos e históricos das comunidades, mais do que apenas por instâncias técnicas. De fato, informação, conhecimento e inovação são as fontes primordiais da produtividade econômica e do emprego, e isto já bastaria para the conferir importância substancial, embora o olhar da cidadania necessite ser privilegiado. "Embora a alfabetização esteja baseada no domínio de uma série de habilidades técnicas e cognitivas, tais como ler, escrever, contar e proficiência em mídia, tais habilidades em si mesmas apenas parcialmente dão conta da alfabetização. Como a pesquisa tem mostrado cada dia mais, a alfabetização está fundamentalmente situada e determinada pelos contextos cultural, político e histórico das comunidades nas quais é ativada. Reconhecese hoje que alfabetização não só implica encaixe lingüístico e social, mas igualmente que é um contínuo de níveis múltiplos e que, ao final das contas, aponta para a identidade cultural de cada qual. Este processo cultural profundo é hoje empurrado para frente pelas oportunidades crescentes que as ferramentas tecnológicas permitem ao interagirem com informação e conhecimento. Três abordagens complementares à alfabetização comparecem na análise educacional: um modelo autônomo de alfabetização, baseado no pressuposto de que ler e escrever são simplesmente habilidades técnicas; um modelo sociocultural, baseado no reconhecimento de todas as alfabetizações como encaixadas social e ideologicamente; e um modelo de forte clamor, baseado nos estabelecimentos antropológicos do poder revolucionário de processos ins- trumentais de pensamento" (BÉLISLE, 2006, p. 52). Sob os auspícios da identidade sóciohistórica, o manejo das novas tecnologias precisa ancorar-se na consciência social e reflexão crítica, tendo em vista conseguir monitorar a mudança pessoal e social ${ }^{3}$.

Como sugeria Paulo Freire, alfabetização emerge como prática sociocultural, realçando acesso e entendimento das estruturas de poder e autoridade em sociedade. Após 1990, que foi o ano da alfabetização, o conceito de estar alfabetizado alargou-se, incluindo pelo menos três desideratos: pensar criticamente, ser aprendiz permanente, dominar a interação com informação tecnologicamente baseada. Tais desideratos tendem a ser expectativas teóricas, porquanto a prática persiste instrucionista, em especial num país como o Brasil (DEMO, 2004a). Ainda assim, torna-se clara a perspectiva do empoderamento intelectual. Para além de tratar textos e números em contextos específicos culturais e ideológicos, a alfabetização traria uma transformação profunda das capacidades humanas de pensar. "Este empoderamento intelectual acontece sempre que a humanidade se apetrecha com novas ferramentas cognitivas, tais como escrever, ou com novos instrumentos tecnológicos, tais como esses que a tecnologia digital tornou possíveis" (BÉLISLE, 2006, p. 54).

Ao mesmo tempo, a definição de conhecimento também sofre mudanças importantes. Como questão epistemológica comple$x a$, conhecimento é muito mais que informação transmitida. "É a consciência e entendimento dos fatos, verdades ou crenças

\footnotetext{
3 "O conceito inicial de alfabetização como referindo-se à aquisição dos três erres, reading, 'riting and 'rithmetic, está ainda muito vivo apesar de suas restrições terem sido questionadas pelos acadêmicos que ser referem a esta abordagem como 'autônoma' ou a visão de 'alfabetização per se'. Como estudos sociológicos trouxeram à luz, esta alfabetização 'neutra e universal' esconde uma agenda de valores, comportamento e estórias de sucesso que os proponentes da alfabetização funcional tendem a considerar como universal, mas que privilegiam os resultados que resultam do encaixe cultural das habilidades alfabéticas. Daí a emergência de uma abordagem mais globalizante em termos não só das habilidades, mas da competência, como uma capacidade subjacente para conhecer que habilidades usar em diferentes contextos e ser capaz de ativar instantaneamente as habilidades pertinentes à tarefa à mão" (BÉLISLE, 2006, p. 53).
} 
resultantes da percepção, aprendizagem e raciocínio, e que podem ser entendidos como resultantes da experiência integral de quatro processos cognitivos básicos: i) a organização de unidades de informação em todos coerentes ou a construção de fatos, estórias, raciocínios, tornando as unidades inteligíveis; ii) a contextualização desses fatos, referindo-os à experiência prévia e conhecimento existente; iii) a interpretação semântica, a invenção de significado ou capacidade de decisão acerca do que se trata nos fatos, estórias, raciocínios; iv) a consciência por parte do cognoscente de que entendeu, ou consciência de novo conhecimento resultante" (BÉLISLE, 2006, p. 57). Percebe-se que conhecimento é dinâmica reconstrutiva permanente, não se deixando cristalizar em produtos determinados. Informação, sim, pode ser armazenada, congelada, enviada, transportada. Conhecimento, não. Existe como dinâmica rebelde, cuja energia maior é o questionamento (DEMO, 2005a).

O desenvolvimento e uso de certas habilidades cognitivas podem levar este processo infindo de reconstrução a: i) saber localizar e identificar informação que interessa; ii) conscientizar-se dos inúmeros contextos; iii) avaliar origem, confiabilidade e propriedade da informação; iv) discernir, escoIher e organizar informação percebida como relevante; v) discriminar, interpretar e analisar criticamente; vi) condensar, sumariar informação, conferindo-lhe novo formato; vii) modelar e estruturar informação, tendo em vista acentuar a autoria; viii) avaliar criticamente, colocando em perspectivas alternativas, comparar e apontar para características específicas. $\bigcirc$ conhecimento cotidiano - aquele que Santos (1995) chama de novo senso comum - torna-se multicultural, multilingüístico e multimodal, porque mudam as fontes de conhecimento acadêmico, surgem novas autoridades legitimadoras de conhe- cimento, aparece o conhecimento como comodidade econômica no ambiente de trabalho. $\bigcirc$ conhecimento inteiro não está na internet, como aposta Breck (2006), até porque na internet está mais propriamente informação disponível que pode virar conhecimento se for reconstruída. Temos na internet, cada vez mais, também informação sofisticada sobre pesquisas de profundidade, mas a tendência é prevalecerem modos mais populares de informação, tal qual sucede na wikipedia: há nela alhos e bugalhos, coisas de elevado nível e coisas primárias; mas tem a graça insubstituível do conhecimento tecido a muitas mãos (TAPSCOTT; WILLIAMS, 2007). O conhecimento interativo dificilmente atinge verticalidade epistemológica que a pesquisa solitária ou rebuscada tem condição de apresentar, até porque o que é comum tende, em geral, a ser medíocre. Aquilo em que todo mundo acredita só pode ser medíocre porque a negociação comum conduz naturalmente a aceitar o que poderia ser comum. Mas, tornando-se este novo tipo de senso comum o espaço público da construção comum de conhecimento, será ele que decidirá as oportunidades disponíveis. A computação, entretanto, não pode substituir a interpretação. É fortíssima a tendência reprodutivista na internet: tudo se copia, nada se cria. Mas é o abuso, que não tolhe o uso. $\bigcirc$ processamento de informação usa algoritmos e regras, enquanto a interpretação realça significados culturalmente encaixados e socialmente negociados. Preocupação maior é o conservadorismo do professor que não se dispõe a assumir esta revolução.

Kope (2006), por sua vez, acentua a importância que ainda se deve dar à alfabetização acadêmica, por reconhecer que o manejo científico dos problemas e desafios é habilidade fundamental de nossa sociedade informacional. A alfabetização com- 
putacional abrange espectro amplo de alfabetizações correlatas, como alfabetização digital, de rede, de TICs, eletrônica, de internet e de hiper-alfabetização, e que são condições importantes para se tornar "fluente" em tecnologia da informação. $\bigcirc$ relatório norte-americano de 1999 sobre "Being fluent with information technology (Sendo fluente em tecnologia da informação), aponta três tipos de conhecimento necessários: habilidades contemporâneas, conceitos fundamentais e [...] capacidades intelectuais. Esta percepção é interessante porque privilegia habilidades propedêuticas genéricas acima do manejo apenas técnico.

O termo 'alfabetização acadêmica' é usado para descrever as habilidades que os estudantes necessitam para terem sucesso num ambiente de educação superior, e mais especificamente como 'um conjunto de comportamentos peculiares aos formalmente educados e 'a habilidade de operar dentro de textos e gêneros das tradições ocidentais, e engajar-se em certos processos de ler e escrever reflexivos desses textos e gêneros' (KOPE, 2006, p. 71).

Isto inclui:

i) pensamento crítico e analítico; ii) solução de problemas; iii) estratégias de estudo de disciplinas específicas; iv) escuta atenta e aprendizagem de aulas; v) habilidades de leitura avançada; vi) aprendizagem de expressões visuais (gráficos, diagramas, animações, etc.); vii) preparação de exame e estratégias de escrita; viii) habilidades de apresentação; ix) concentração e memória; x) tempo, tarefa de trabalho e autogestão; xi) habilidades grupais; xii) aprendizagem com e de tecnologias (KOPE, 2006, p. 71).

contexto cheira a algum instrucionismo, sobretudo quando se louva a escuta de aulas e a memorização, mas, no todo, acentua-se o espírito crítico. Há que se levar em conta que a "tecnologia aprimora o acesso físico à informação, mas não necessariamente aprimora o acesso intelectual (KOPE, 2006, p. 75). Por isso, habilidades de interpretação são mais importantes, incluindo: integrar nova informação em corpo existente de conhecimento; tratar com fontes de informação também fora da biblioteca; aplicar princípios em outros contextos; comunicar informação com autoria.

Chama a atenção a insistência sobre a importância do pensamento crítico, com objetivo de superar a mera transmissão de informação. Como diz Pilerot (2006), quem cuida da informação - neste caso, o bibliotecário - precisa tornar-se "educador", porque estar alfabetizado em informação implica ser capaz de reconhecer a informação necessária, ter habilidade de localizar e avaliar, bem como de usar efetivamente. Para Warlick (2006, p. 91), as maiores habilidades requeridas são: i) encontrar informação; ii) decodificar informação; iii) avaliar criticamente a informação; iv) organizar informação. No contexto do cidadão como mero consumidor de informação, Hobbs (2006) propõe uma reconceituação da alfabetização em mídia, com vistas a analisar criticamente as notícias construídas e entender sua função na sociedade, sempre dúbia. Em especial o advertising merece atenção crítica redobrada, porque, ao fundo, espera-se que o espectador engula a mensagem em nome do consumo. Há também que examinar padrões de representação de raça, gênero e do papel da violência, tendo em mente formar pensadores críticos. Outros autores, como Sutton (2006) satisfazem-se com resultados mais modestos, qual seja o papel possível do ensino on-line para trabalhadores, permitindo que eles re-entrem na força de trabalho, se re-treinem para um novo emprego e elevem suas habilidades no emprego existente. 


\section{Novas linguagens}

Quanto mais nova a criança, mais seu futuro será condicionado pela alfabetização digital. A escola precisa respeitar este direito de aprender da criança, para que esta possa preparar-se para o mundo real no qual vai viver quando adulta. Marsh (2005b) editou uma obra muito interessante sobre tal desafio, discutindo cultura popular, nova mídia e alfabetização digital na primeira infância.

A preocupação em não expor a criança cedo demais ou em demasia ao computador pode ser congruente, mas não pode empanar o desafio da criança de dar conta do computador como sujeito que sabe usar e questionar. Ainda que possivelmente entusiasmado demais, Tapscott (1998) já acenara para o desafio da net generation, que cresce digitalmente. Marsh entende por cultura popular os textos culturais, artefatos e práticas que são atrativos para grandes números de crianças e que são muitas vezes produzidos em massa numa escala global. Nova mídia pode incluir jogos de computador, feitura de mensagens de texto em telefones móveis, uso de TV interativa, com ênfase na tecnologia de tela (screen-based), demandando análise acurada "em termos de práticas de produção de significado por parte de crianças pequenas" (MARSH, 2005 b, p. 4). Como outros autores, Marsh fala ostensivamente de "alfabetizações".

Para alguns pesquisadores, mudanças em tecnologias de comunicação alteram a estrutura de pensamento, o caráter dos símbolos e a natureza da comunidade, porque mudanças nos modos pelos quais somos capazes de nos comunicar guardam impacto sobre o que pensamos, as ferramentas que usamos para pensar e o contexto no qual elaboramos este pensamento (CARRINGTON, 2005). Esta visão parece tender a certo determinismo tecnológico, mas pode ser bem entendida como influência mútua e complexa entre sociedade e meios de comunicação. Se, de um lado, a inovação tecnológica em comunicação força a mudar como vemos a nós mesmos no mundo e os modos nos quais este mundo opera, de outro, vale reconhecer que a emergência de novas tecnologias de comunicação proporciona novas energias que levam a reformatar discursos dominantes. Leve-se em conta que as inovações impactam em primeiro lugar as crianças, do que decorre responsabilidade particular dos educadores. Algumas mudanças são: i) pessoas mais jovens estão imersas em cenários textuais que não são mais dominados pela imprensa, o que já altera as expectativas de alfabetização e mundo do trabalho, tendo em vista seu direito de preparar-se adequadamente para o futuro; ii) muitos dos cenários textuais provêm de fora da escola ou da família, predominando o contexto da cultura popular e dos textos eletrônicos emergentes, muitas vezes ultrapassando ou subvertendo o olhar supervisor e controlador dos adultos; iii) decorrem implicações para os modos como construímos a infância na sociedade contemporânea ocidental, não mais centrada em designs disciplinares; seu acesso e domínio de novos textos e alfabetizações como weblogs, e-zines, jogos de computador, internet e txting lhes proporciona condição sem precedentes e muitas vezes independente ao mesmo pool de informação dos adultos; mais ainda, tais textos e tecnologias facultam as crianças tornarem-se produtoras e disseminadoras de informação (CARRINGTON, 2005, p. 14).

Marsh usa o termo textual landscapes (cenários textuais), de estilo multidimensional e multimodal, nos quais e através dos quais organizamos nossas vidas numa sociedade rica em texto. $\bigcirc$ espaço de leitura, antes restrito a expressões impressas, alarga-se quase que infinitamente nos cenários eletrônicos, 
com a vantagem de permitirem autoria mais efetiva. "Minha tese é que novas tecnologias de comunicações e a emergência associada de novos textos e práticas de alfabetização mudaram o modo como pessoas jovens entendem a si mesmas e o mundo" (MARSH, $2005 a$, p. 22). Esta maneira de colocar cheira a determinismo tecnológico, porque deixa de lado que as tecnologias não apenas influenciam a sociedade, como também são influenciadas pela sociedade. Afinal, as tecnologias não teriam surgido se a sociedade não as valorizasse e inventasse. Questão crucial é a da identidade (Marsh, 2005c): desaparece a noção essencialista de identidade, para dar lugar a contextos mais dialéticos e complexos, porquanto só permanece na história o que muda. Não se dilui na efemeridade, porque, ao institucionalizar-se, ganha condições de alguma permanência. No entanto, mudar é maneira de permanecer (BAUMAN, 2001).

Resultado importante deste tipo de análise é o reconhecimento da necessidade de superar a idéia tradicional da passividade e ignorância da criança (ROBINSON; TURNBULL, 2005). $\bigcirc$ fato corrente de que a criança se vira melhor no computador que os adultos levou-nos a rever a noção clássica da criança como impotente e entregue à decisão adulta. Evidentemente, a criança precisa de apoio dos adultos, porque a autonomia humana somente se desenvolve com apoio (DEMO, 2005a), mas, no contexto das novas tecnologias, a criança mostra familiaridade que o adulto em geral não consegue ter. Ainda que não saibamos explicar esta habilidade infantil de maneira adequada, não escapamos de a reconhecer. De igual maneira, contesta-se hoje que a criança não tenha atenção suficiente para acompanhar programas mais longos (ROBERTS; HOWARD, 2005), porquanto depende, antes de mais nada, de interessar à criança. Quanto sugerimos - algo freqüente na escola - que a criança de hoje já não se interessa por nada, esquecemos que não se interessa pela escola, mas interessa-se por outros linguagens, como as digitais, por vezes de maneira excessiva.

Há que se levar em conta que saber escrever sempre foi caminho de acesso ao poder, não sendo diferente para as crianças. Elas se sentem poderosas ao manipularem com autonomia o computador e a internet. Por isso é essencial educá-las para controlarem as tecnologias e interferirem nas práticas sociais. Em termos de acesso, precisam de pouca ajuda, mas em termos de autoria de escrita na tela podem ser auxiliadas por educadores capazes de fomentar sua habilidade de sujeitos (MERCHANT, 2005). Vasques (2005), referindo-se ao ambiente atraente da cultura popular digital, ressalta que, apesar dos riscos de atrelamento ao consumo, há espaço para negociar, não sendo correta a noção tradicional de passividade infantil. É preciso levar em conta que as crianças facilmente se identificam com expressões da nova mídia, por vezes em excesso, mas a postura inteligente não é proibir, censurar, mas educar para o bom uso. Vasques relata que, impedindo as crianças de brincarem com Pokémon, quando solicitadas a fazerem texto, o faziam sobre Pokémon. Neste contexto, há que fazer dupla consideração crítica: i) o mercado liberal produz textos digitais de grande atração e consumo, induzindo a dependências unilaterais; ii) como não cabe a política do avestruz, a solução mais inteligente é educar para o tratamento crítico das novas linguagens. Por isso, aspecto primordial das novas alfabetizações é sua exigência crítica, no sentido de produzi-las e usá-las para exercer poder, aprimorar a vida cotidiana nas escolas e comunidades, questionar práticas de privilégio e injustiça (VASQUES, 2005). Neste sentido, é interessante a experiência apresentada por Nixon e Comber (2005) de per- 
mitir que crianças pequenas façam filmes, se com eles elas se tornarem pesquisadoras de linguagem e cultura. Não está em questão a qualidade cênica dos filmes, mas a habilidade de produzir sentidos com base em novas tecnologias e respectivas linguagens, privilegiando estilos situados de aprendizagem.

Marca crucial dessas novas linguagens é sua tessitura virtual, um modo de lidar com a realidade que pode ser realista, mas não real. Pode ser realista quando, por exemplo, uma construção em 3D se assemelha muito ao mundo real. Não pode ser real, porque é uma construção ou reconstrução. Neste sentido, o virtual não é apenas expressão digital eletrônica, mas propriedade da mente. Captamos a realidade não pela via da representação (SFEZ, 1994), como se fosse xérox, mas pela via da intermediação interpretativa, reconstrutiva dos sentidos e do cérebro. Esta característica faz parte da autopoiese (MATURANA, 2001), de teor autoreferente e reconstruivo, na condição de observador ativo. Poderíamos, assim, afirmar que a produção de uma teoria faz parte da mesma dinâmica mental. Teoria trabalha com "objeto construído" (DEMO, 1985), não com a realidade diretamente, ou, como dizem outros, com um modelo simplificado de realidade. Como no texto eletrônico, que é reduzido a seqüências algorítmicas, na teoria a realidade é reduzida a suas estruturas mais centrais. Este reducionismo inevitável é tido como aceitável na discussão metodológica, já que é próprio da mente padronizar as dinâmicas para torná-las mais manejáveis (HAACK, 2003). Como isso, temos de aceitar que não estudamos a dinâmica como tal, mas os padrões da dinâmica, ou seja, o que não é dinâmico na dinâmica. Algo muito similar ocorre na linguagem digital: é fortemente padronizada em algoritmos, que indicam sua estrutura, não sua dinâmica. Mas como nem as teorias, nem a linguagem eletrônica são propriamente reais, constituem-se como abordagens variavelmente construídas de realidades no fundo indevassáveis (DEMO, 2002a). Podem ser tão bem feitas que parecem reais e há quem diga que, por vezes, o mundo virtual parece mais real que o real.

O virtual, fazendo parte da realidade, não pode ser irreal, fantasmagórico, ainda que seja sempre um simulacro, no sentido de simular a realidade de maneira interpretativa. Neste sentido, Gee (2007) baseia sua noção de aprendizagem situada no mundo virtual, de maneira surpreendente. Muitos diriam que situar algo só poderia significar sua inserção na realidade concreta, não no mundo virtual. Ocorre que, se temos do virtual noção apenas fantasmagórica, não pareceria real. Mas como modo inteligente e pertinente, interpretativo e reconstrutivo da realidade, o virtual refere-se ao mundo real, permitindo sua manipulação pelo autor. Nos jogos eletrônicos esta marca é cada vez mais ressaltada: nos bons jogos eletrônicos, o jogador é imbuído de autoria, ainda que sempre limitada, podendo, além de assumir um avatar, mudar regras de jogo e construir ambientes digitais. Dito de outro modo, o jogador sente-se poderoso, porque mexe no jogo, não apenas segue regras, mas faz algumas delas (PRENSKY, 2001, 2006). Sobretudo o artifício engenhoso da computação gráfica em três dimensões capacita a linguagem digital imprimir à aprendizagem a marca do conhecimento situado, vivo e atraente.

A realidade é, no fundo, não linear, mas apresenta-se também de maneira linear, o que permite a digitalização. Munster, ao discutir a incorporação nos processos de informação, cita uma passagem de De Landa (1997 apud MUNSTER, 2006, p. 1):

Nosso mundo é governado não só por dinâmicas não lineares, que tornam predi- 
ções e controle detalhados impossíveis, mas igualmente por combinatórias não lineares, que implicam que o número de misturas possíveis de sistemas de malhas e hierarquia, de comando e mercado, de centralização e descentralização sejam imensas e que simplesmente não podemos predizer quais serão as propriedades emergentes dessas combinações.

Munster (2006) quer sustentar que a digitalização da linguagem pode parecer um empobrecimento, pois é reduzida a algoritmos seqüenciais, mas isto não desfaz o fato de que se trata de fluxo de informações, que são referenciados pela base digital, mas admitem toda sorte de interpretação e reconstrução. Se a própria linguagem digital é uma reconstrução, não se trata de uma modelização que resseca o espírito, mas também o pode libertar.

Para começar, a virtualidade não existe fora da experiência corporal, por mais que a expressão virtual pareça uma ossatura mínima e minimalista. Sendo produto mental, tem a marca da mente que é, sempre também, matéria corporal (VARELA; THOMPSON; ROSCH, 1997). O virtual não é fuga, mas outro modo de incorporação. A seguir, "o virtual não é da ordem da representação; o que quer dizer, não procede da realidade. Nem precede o real como idealidade, modelo ou simulação. É, ao contrário, um conjunto de movimentos potenciais produzidos por forças que diferencialmente trabalham através da matéria, resultando na atualização desta matéria sob condições locais" (MUNSTER, 2006, p. 90). Ao contrário de uma ampla literatura que descreve o ciberespaço como contrário ao corpo - uma das marcas dessa visão é livrar-se do corpo, por ser expressão limitada e obsoleta (SILVA, 2002; HARAWAY, 1991) -, Munster busca mostrar que a construção virtual é sempre, naturalmente, ex- pressão também corporal, ainda que montada digitalmente (HAYLES, 1999; 2005). Por fim, o design virtual permite, surpreendentemente, situar-nos no mundo real, um princípio fundamental da aprendizagem. Por isso Gee (2004) sempre lembra que bons videogames transpiram bons princípios de aprendizagem.

mundo virtual oferece condições inestimáveis de aprendizagem pertinente, desde que se supere a tendência instrucionista em geral também avassaladora. Hoje a internet é vista muito mais como meio de plágio do que de pesquisa. $\bigcirc$ desafio é fazer dela um ambiente propício para pesquisa e elaboração própria, resultando na autoria dos alunos. Uma tecnologia conhecida é do blog e wikipedia em sites pessoais, porque faculta a feitura de textos de toda ordem, desde os apenas impressos, até os mais animados, abrindo para os estudantes horizontes de uma pluralidade imensa de textos alternativos. A máquina aí está, com suas virtudes e limites, e sempre em mudança acelerada tecnológica. $\bigcirc$ desafio é saber o que fazer dela. Pode-se apenas transmitir informação, reproduzir textos alheios, plagiar fraudulentamente. Mas pode-se também motivar os alunos a tornarem-se autores cada vez mais interpretativos, criativos e críticos. Trata-se, ademais, de ambiente interessante para as alfabetizações, no qual a alfabetização tradicional aparece logo como mero pressuposto. Sendo os sites pessoais acessíveis, pode-se acompanhar o processo de construção de textos dos alunos, o que facultaria um tipo de transparência e visibilidade que a escola nunca tem. Em vez de ser uma caixa preta o que acontece em sala de aula, o uso dessas tecnologias tornaria as dinâmicas acessíveis, permitindo avaliações externas pertinentes. Enquanto o blog permite o controle pessoal (senha) dos textos, a wikipedia é livre. Ambos os modos são fundamentais, mas talvez 
o da wikipedia esteja ganhando ascendência, porque representa a ideagora (praça de idéias) mais visível no momento, na qual a construção interativa de idéias corre solta e pode ser muito criativa (TAPSCOT; WILLIAMS, 2007). Como sugere Duderstadt (2003), a riqueza das nações constitui-se hoje de gente educada e suas idéias. $\bigcirc$ mundo virtual precisa servir a este objetivo: criar idéias, promover o saber pensar.

A escola, em especial a escola pública, está muito distante de tais desafios, em grande parte porque se fechou em didáticas ultrapassadas e que não sabe questionar. São didáticas faz-de-conta, porque não têm mais qualquer repercussão significativa no mundo real, em particular no futuro das crianças. Essas, quando adultas, terão de lidar com o mundo virtual, o computador, a internet, não só no trabalho, mas na vida em geral. As linguagens virtuais serão preponderantes e será dessas que lançarão mão para dar sentido à realidade. $\bigcirc$ primeiro problema está na formação original dos docentes, em geral completamente distanciada das novas linguagens (DEMO, 2007b). Pedagogia e licenciaturas, cada vez mais, decaem para cursos encurtados e aviltados, nos quais é impraticável uma formação qualitativa. $\bigcirc$ resultado é que nossos formadores não são bem formados. $\bigcirc$ segundo problema é que, estando em atividade docente, os professores não continuam estudando profissionalmente. Apenas dão aula, porque foram (de)formados por aulas. Professor que não sabe aprender bem não pode cuidar da aprendizagem dos alunos. $O$ terceiro problema aparece na pedagogia tradicionalista escolar, da qual não faz parte o mundo virtual. No máximo, existe na escola um laboratório de informática, de estilo preliminar, para eventuais voluntários e que não conseguem implantar a informática na aprendizagem do aluno, por mais que seja usada intermitente e amadoramente.
Se fôssemos minimamente justos com as crianças, deveriam ser alfabetizadas com computador, porque já agora, mas principalmente no futuro, precisarão deste tipo de linguagem impreterivelmente. $\bigcirc$ texto impresso não vai desaparecer, mas não será preponderante. Os modos de comunicação e interação assumem outras urdiduras textuais que, além de mais atraentes e motivadoras, parecem - por conta da reconstrução virtual - mais reais. Estamos aí perante um impasse duplo: grande parte dos alfabetizadores não sabem alfabetizar, porque o curso que fizeram não era profissional; nem todos sabem lidar com o computador para alfabetizar. Evidentemente que este tipo de problemática não se supera da noite para o dia. Nosso atraso vai custar-nos caro, mas é possível ir pensando em como dar conta dele. Será impreterível organizar escolas nas quais o computador faça parte inarredável da aprendizagem dos alunos, de modo progressivo e sistemático, até que todo o ambiente esteja inserido nas novas tecnologias. Não é o caso imaginar que o aluno só use o computador. Precisa também aprender a escrever com a mão, a ler fora da tela, a apreciar literatura clássica. Mas seu ambiente mais próprio de aprendizagem será o virtual. A informática deixará de ser laboratório eventual e secundário, para tornar-se ambiente mais apropriado de aprendizagem, desde que se supere o instrucionismo.

É preciso, ademais, manter o espírito crítico também frente à nova mídia. Quando escutamos o entusiasmo de muitos autores com referência ao pensamento crítico possível em ambientes virtuais, parece o canto da sereia, tal qual a conversa pedagógica sobre transformação social (DEMO, 2000). Conversase tanto sobre isso que mais parece tática de digressão, já que transformação social é o que menos se vê. Ao contrá- 
rio, aprende-se no Brasil, ano após ano, menos. Sobretudo obras americanas, muitas vezes subservientes ao mercado liberal, banalizam o que chamam de pensamento crítico, porque apenas apreciam sua qualidade formal, não a política (POPKEWITZ, 2001). O mundo das novas tecnologias é um mundo também desigual, não faltando autores que vêem a digital divide se aprofundando (DIJK, 2005; WARSCHAUER, 2003). A desigualdade não diminui pela tecnologia, mas pela cidadania (BARD; SÖDERQVIST, 2002). Por conta do ambiente capitalista (LIU, 2004), medra nos porões da produtividade um cybertariat (proletários cibernéticos) (HUWS, 2003). Facilmente deixa-se de lado que toda esta inovação está atrelada umbilicalmente ao mercado liberal, no qual o ser humano também aparece como mercadoria (MOSSBERGER; TOLBERT; STANSBURY, 2003).

A exigência do aprimoramento crítico faz todo sentido, mas dificilmente aparece alguma sugestão de como isso poderia ser atingido, em especial o papel dos professores. Facilmente reclama-se de sua resistência (STOLL, 1999), sem levar em conta que, para além da formação muito deficitária, muitos não teriam recursos financeiros para ter em casa um computador moderno e uma internet de banda larga (UNESCO, 2004). As condições de trabaIho facilmente são aviltantes, também no aspecto físico, o que impediria, entre outras coisas, imaginar que uma escola dessas ofereça a cada aluno um computador (DEMO, 2007a). O atraso do professor seria, aí, reflexo do atraso de nossas políticas públicas de educação. A maior ironia, entretanto, é que, se ainda sequer sabemos resolver a alfabetização tradicional, pareceria estranho meter-se a resolver a alfabetização digital.

\section{Para concluir}

Preparar-se para a vida, sem falar em preparar-se para o mercado, vai tornandose tarefa cada vez mais complexa. Em parte é apenas conseqüência da complexidade crescente dos contextos atuais de sobrevivência, trabalho e cidadania. Ter um diploma superior era, uma vez, garantia de emprego adequado. Agora, não significa muito, até porque, na sociedade intensiva de conhecimento, nenhum diploma se sustenta por muito tempo. Menos que domínio de conteúdos, exigem-se hoje várias propedêuticas, em especial duas: saber inglês fluentemente e dominar informática. A alfabetização tradicional vai desaparecendo no horizonte como simples pressuposto, com o qual já as crianças não perdem muito tempo. Se têm acesso ao computador, vão resolvendo isso naturalmente, sem querer, à medida que, tateando para todos os lados, descobrem as letras e os números, e, brincando disso ou daquilo, vão formando palavras e contas. Isto não elimina a oportunidade de aprender de maneira sistemática ler, escrever e contar. Mas, nem de longe, é uma alfabetização suficiente, muito menos é " $a$ " alfabetização.

A escola, todavia, persiste nesta alfabetização e que, sarcasticamente, faz muito mal. Não conseguimos mais alfabetizar na $1^{a}$ série, e, para muitos casos, esta alfabetização não se conclui nunca. Ainda é comum que alunos da $9^{a}$ série leiam, mas não entendam o que lêem. São, pois, analfabetos, no sentido maior deste termo: não sabem pensar. A escola, assim, não prepara para a vida, porque negam-se aos alunos inúmeras outras alfabetizações, em especial as digitais. Se já muitos ficavam para trás por não deterem a alfabetização tradicional, não atingir outras alfabetizações, em particular as digitais, vai tornando-se um fator drástico de exclusão social. 


\section{Referências}

ALVES-MAZOTTI, A. J. et al. Linguagens, espaços e tempos no ensinar e aprender. Rio de Janeiro: DP\&A, 2001.

BAKAN, J. The corporation: the pathological pursuit of profit and power. New York: Free Press, 2004.

BARD, A.; SÖDERQVIST, J. Netocracy: the new power elite and life after capitalism. London: Reuters, 2002.

BAUMAN, Z. Modernidade líquida. Rio de Janeiro: Zahar Ed., 2001.

BÉLISLE, C. Literacy and the digital knowledge revolution. In: MARTIN, A.; MADIGAN, D. (Ed.). Digital literacies for learning. London: Facet Publishing, 2006.

BOGOST, I. Unit operations: an approach to videogame criticism. Massachusetts: The MIT Press, 2006.

BOURDIEU, P.; PASSERON, J. C. A reprodução: elementos para uma teoria do sistema educativo. Rio de Janeiro: Francisco Alves, 1975.

BRAUDEL, F. La dinámica del capitalismo. México: Fondo de Cultura Económico, 1993.

BRECK, J. 109 Ideas for virtual learning: how open content will help close the digital divide. Oxford: Roman \& Littlefield Education, 2006.

CARRINGTON, V. New textual landscapes, information and early literacy. In: MARSH, J. (Ed.). Popular culture, new media and digital literacy in early childhood. New York: Routledge Falmer, 2005.

CASTELLS, M. The rise of the network society. Malden, Mass.: Blackwell, 1997. (The information age. Economy, society and culture; v. 1).

CRONJÉ, J. Real learning in virtual environments. In: MARTIN, A.; MADIGAN, D. (Ed.). Digital literacies for learning. London: Facet Publishing, 2006.

DE LANDA, M. A thousand years of nonlinear history. New York: Zone Books, 1997. (Swerve Editions).

DEMO, P. Aposta no professor: cuidar de viver e de trabalhar com dignidade. Porto alegre: Mediação, 2007a.

Aprendizagem no Brasil: ainda muito por fazer. Porto Alegre: Mediação, 2004a. Argumento de autoridade $x$ autoridade do argumento. Rio de Janeiro: Tempo Brasileiro, 2005a. 
DEMO, P. Complexidade e aprendizagem: a dinâmica não linear do conhecimento. São Paulo: Atlas, 2002a.

. Conhecimento e aprendizagem na nova mídia. Brasília, DF: Plano, 2001.

. Éticas multiculturais: sobre convivência humana possível. Petrópolis: Vozes, 2005b.

- Introdução à sociologia: complexidade, interdisciplinaridade e desigualdade

social. São Paulo: Atlas, $2002 b$.

2000

. Ironias da educação: mudança e contos sobre mudança. Rio de Janeiro: DP\&A,

. Leitores para sempre. Porto Alegre: Mediação, 2005c.

. Metodologia científica em ciências sociais. São Paulo: Atlas, 1985.

. O porvir: desafio das linguagens do século XXI. Curitiba: IBPEX, 2007b.

. Ser professor é cuidar que o aluno aprenda. Porto Alegre: Mediação, 2004b.

. Sociologia da educação: sociedade e suas oportunidades. Brasília, DF:

LiberLivro, 2004c.

DIJK, J. A. G. M. The deepening divide: inequality in the information society. London:

Sage Publications, 2005.

DUDERSTADT, J. J. A university for the 21 st Century. Ann Arbor: The University of Michigan Press, 2003.

DUPAS, G. O mito do progresso. São Paulo: Ed. UNESP, 2006.

GARDNER, J. The Intelligent Universe: Al, ET, and the emerging mind of the cosmos.

Franklin Lakes, NJ: New Page Books, 2007.

GEE, J. P. Good video games + good learning. New York: Peter Lang, 2007.

Situated language and learning: a critique of traditional schooling. New York:

Routledge, 2004.

GILSTER, P. Digital fusion: defining the intersection of content and communications. In: MARTIN, A.; MADIGAN, D. (Ed.). Digital literacies for learning. London: Facet Publishing, 2006.

GOULD, S. J. The structure of evolutionary theory. Cambridge, MA: The Belknap Press of Harvard Univ., 2002.

HAACK, S. Defending science within reason: between scientism and cynicism. New York: Prometheus Books, 2003. 
HARAWAY, D. J. Simians, cyborgs, and women: the reinvention of nature. New York: Routledge, 1991.

HAYLES, N. K. How we become post-human: virtual bodies in cybernetics, literature, and informatics. Chicago: The University of Chicago Press, 1999.

My mother was a computer: digital subjects and literary texts. Chicago: The University of Chicago Press, 2005.

HOBBS, R. Reconceptualizing media literacy for the digital age. In: MARTIN, A.; MADIGAN, D. (Ed.). Digital literacies for learning. London: Facet Publishing, 2006.

HUWS, U. The making of a cybertariat: virtual work in a real world. New York: Monthly Review; London: The Merlin Press, 2003.

IOSCHPE, G. A ignorância custa um mundo: o valor da educação no desenvolvimento do Brasil. São Paulo: Francis, 2004.

KOPE, M. Understanding e-literacy. In: MARTIN, A.; MADIGAN, D. (Ed.). Digital literacies for learning. London: Facet Publishing, 2006.

KURZWEIL, R. The singularity is near: when humans transcend biology. New York: Viking, 2005.

LENSKI, C.; LENSKI, J. Human societies: an introduction to macro sociology. New York: McGraw-Hill, 1987.

LIU, A. The laws of cool: knowledge work and the culture of information. Chicago: The University of Chicago Press, 2004.

MANGUEL, A. Uma história da leitura. São Paulo: Companhia das Letras, 1996.

MARSH, J. Introduction: children of the digital age. In: MARSH, J. (Ed.). Popular culture, new media and digital literacy in early childhood. New York: RoutledgeFalmer, $2005 a$.

. Ritual, performance and identity construction: young children's engagement with popular cultural e media texts. In: MARSH, J. (Ed.). Popular culture, new media and digital literacy in early childhood. New York: RoutledgeFalmer, 2005b.

. (Ed.). Popular culture, new media and digital literacy in early childhood. New York: RoutledgeFalmer, 2005c.

MARTIN, A. Literacies for the digital age: preview of part I. In: MARTIN, A.; MADIGAN, D. (Ed.). Digital literacies for learning. London: Facet, 2006.

MARTIN, A.; MADIGAN, D. (Ed.). Digital literacies for learning. London: Facet, 2006.

MATURANA, H. Cognição, ciência e vida cotidiana. Organização de C. Magro e V. Paredes. Belo Horizonte; Ed. Humanitas: UFMG, 2001. 
MATURANA, H.; VARELA, F. De máquinas y seres vivos: autopoiesis: la organización de lo vivo. Santiago: Editorial Universitária, 1994.

MAYES, T.; FOWLER, C. Learners, learning literacy and the pedagogy of e-learning. In: MARTIN, A.; MADIGAN, D. (Ed.). Digital literacies for learning. London: Facet Publishing, 2006.

MERCHANT, G. Barbie meets Bob the builder at the workstation: learning to write on screen. In: MARSH, J. (Ed.). Popular culture, new media and digital literacy in early childhood. New York: RoutledgeFalmer, 2005.

MOSSBERGER, K.; TOLBERT, C. J.; STANSBURY, M. Virtual inequality: beyond the digital divide. Washington, DC: Georgetown University Press, 2003.

MUNSTER, A. Materializing new media: embodiment in information aesthetics. Hannover: Dartmouth College Press, 2006.

NIXON, H.; COMBER, B. Behind the scenes: making movies in early years classrooms. In: MARSH, J. (Ed.). Popular culture, new media and digital literacy in early childhood. RoutledgeFalmer, 2005.

OLIVEIRA, J. B. A.; CHADWICK, C. B. Tecnologia educacional : teorias da instrução. Petrópolis: Vozes, 1984.

PILEROT, O. Information literacy: an overview. In: MARTIN, A.; MADIGAN, D. (Ed.). Digital literacies for learning. London: Facet Publishing, 2006.

POLANYI, K. A grande transformação: as origens da nossa época. Rio de Janeiro: Campus, 2000.

PLANT, S. Mulher digital: o feminino e as novas tecnologias. Rio de Janeiro: Editora Rosa dos Tempos, 1999.

POPKEWITZ, T.S. Lutando em defesa da alma: a política do ensino e a construção do professor. Porto Alegre: Artmed, 2001.

PRENSKY, M. Digital game-based learning. New York: McGraw-Hill, 2001.

. Don't bother me mom: i'm learning!. Minnesota: Paragon House, 2006.

PRIGOGINE, I.; STENGERS, I. A nova aliança. Brasília, DF: Ed. UnB, 1997.

ROBERTS, S.; HOWARD, S. Watching Teletubbies: television and its young audience. In: MARSH, J. (Ed.). Popular culture, new media and digital literacy in early childhood. New York: RoutledgeFalmer, 2005.

ROBINSON, M.; TURNBULL, B. V.. An asset model of becoming literate. In: MARSH, J. (Ed.). Popular culture, new media and digital literacy in early childhood. New York: RoutledgeFalmer, 2005. 
SANTOS, B.S. Toward a new common sense: law, science and politics in the paradigmatic transition. New York: Routledge, 1995.

SFEZ, L. Crítica da comunicação. São Paulo: Loyola, 1994.

SILVA, T. T. Antropologia do ciborgue: as vertigens do pós-humano. Belo Horizonte: Autêntica, 2002.

SOUZA, P. R. A revolução gerenciada: educação no Brasil 1995-2002. São Paulo: Pearson: Prentice Hall, 2004.

STOLL, C. High tech heretic: why computers don't belong in the classroom and other reflections by a computer contrarian. New York: Doubleday, 1999.

SUTTON, C. Literacy, e-literacy and multiliteracies: meeting the challenges of teaching online. In: MARTIN, A.; MADIGAN, D. (Ed.). Digital literacies for learning. London: Facet Publishing, 2006.

TAPSCOTT, D. Growing up digital: the rise of the net generation. New York: McGraw-Hill, 1998.

TAPSCOTT, D.; WILLIAMS, A. D. Wikinomics: how mass collaboration changes everything. London: Penguin, 2007.

UNESCO. O perfil dos professores brasileiros: o que fazem, o que pensam, o que almejam... São Paulo: Editora Moderna, 2004.

VARELA, F. J.; THOMPSON, E.; ROSCH, E. The embodied mind: cognitive science and human experience. Cambridge, Mass.: The MIT Press, 1997.

VASQUES, V. Resistance, power-tricky, and colorless energy: what engagement with everyday popular culture texts can teach us about learning and literacy. In: MARSH, J. (Ed.). Popular culture, new media and digital literacy in early childhood. New York: RoutledgeFalmer, 2005.

VEIGA-NETO, A. Espaços, tempos e disciplinas: as crianças ainda devem ir à escola?. In:

WARLICK, D.F. Contemporary literacy: the three es. In: MARTIN, A.; MADIGAN, D. (Ed.). Digital literacies for learning. London: Facet Publishing, 2006.

WARSCHAUER, M. Technology and social inclusion: rethinking the digital divide. Cambridge, Mass.: The MIT Press, 2003.

WITHROW, F. B. Literacy in the digital age: reading, writing, viewing, and computing. Toronto: ScareCrowEducation, 2004.

Recebido em: 06/08/2007

Aceito para publicação em: 13/11/2007 